[Highlight]

\title{
提升二氧化碳光催化转化选择性的催化位点晶格工程策略
}

\author{
张铁锐 \\ (中国科学院理化技术研究所, 北京 100190)
}

\section{Lattice Engineering on Catalytic Sites for Achieving Highly Selective Photocatalytic $\mathrm{CO}_{2}$ Conversion}

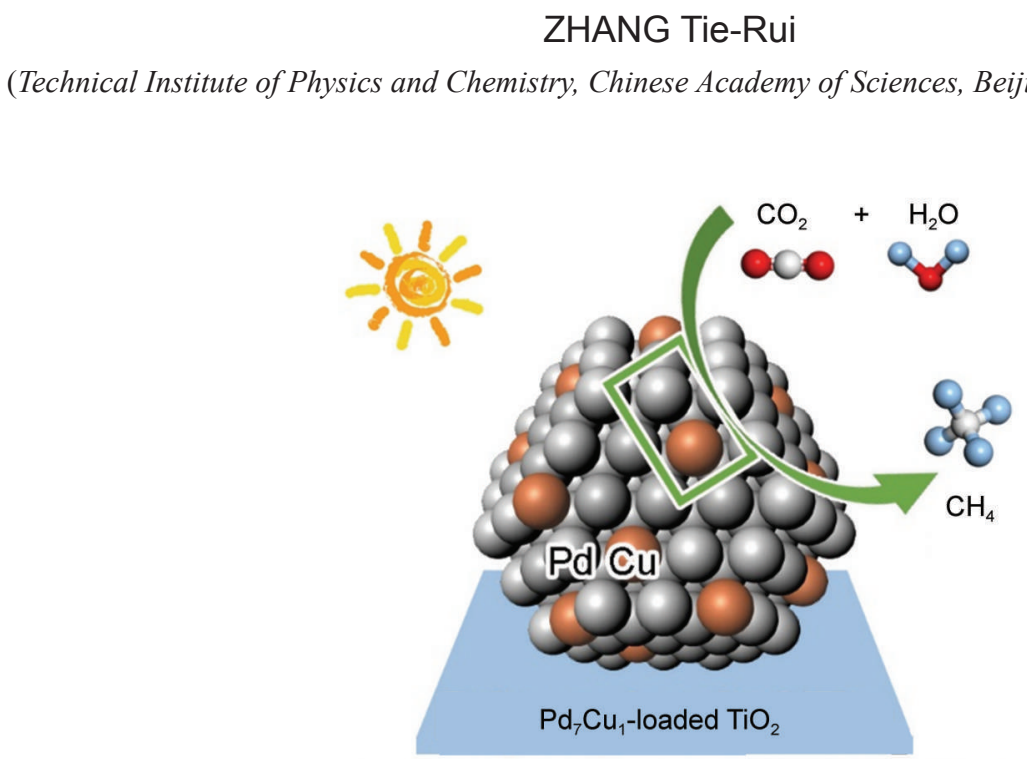

大气中二氧化碳浓度的逐年上升导致了一系 列生态问题, 因此其催化转化成为了能源与环境 领域中的一个重要议题 1,2 。业界针对二氧化碳转 化, 提出通过光催化在常温常压下将二氧化碳与 水转化为碳氢化合物或液体燃料等高附加值化学 品的思路, 可以在治理二氧化碳问题的同时为新 能源的探索提供一个新的途径 ${ }^{3-5}$ 。其中将二氧化碳 与水转化为甲烷的途径尽管有着广阔的前景, 然 而该 8 电子反应过程在催化活性及选择性方面面临 着巨大的挑战。二氧化碳的催化转化主要受到两 方面的限制：(1)二氧化碳分子非常惰性, 限制了 催化转化反应的活性; (2)二氧化碳在还原生成甲 烷的同时会发生许多副反应, 也伴随着质子还原 的竞争反应, 生成一氧化碳或者释放出氢气, 降 低了其催化选择性。

最近中国科学技术大学熊宇杰教授课题组基
于光催化剂的催化位点晶格工程, 发现铜位点在 钯晶格中的单原子分布有利于二氧化碳转化为甲 烷的选择性提升, 相关结果发表在 Journal of the American Chemical Society 杂志上 ${ }^{6}$ 。过去研究表明 铜原子对于二氧化碳分子的吸附与活化展现了良 好特性 ${ }^{7,8}$, 因此可以作为与半导体光催化剂集成的 催化位点。然而纳米尺度下的铜位点很容易被氧 化, 并且通常在催化过程中存在多个反应通道。 作者将铜单原子位点嵌入于钯晶格中, 可以一定 程度上抑制铜的氧化状态。另一方面, 钯晶格的 $\mathrm{Pd}-\mathrm{H}$ 键作用较强, 不利于 $\mathrm{H}_{2}$ 的释放, 能够抑制 光催化转化二氧化碳中的副反应。

作者基于钯铜双金属结构，进一步结合金属 原子分布状态的同步辐射 $\mathrm{X}$ 射线吸收精细谱表征、 二氧化碳分子吸附活化状态的原位红外光谱检测 和铜 $d$ 带中心位置的理论模拟, 揭示了催化位点结 
构与二氧化碳转化性能的构效关系。他们的研究 结果发现, 钯晶格中嵌入的铜单原子结构在提高 光催化二氧化碳转化的活性和选择性中扮演了关 键性的角色: (1) 铜-钯原子对提供了二氧化碳吸附 与活化的位点, 并且抑制了副产物 $\mathrm{H}_{2}$ 的生成; (2) 钯晶格调控了铜位点的 $d$ 带中心位置, 有利于二氧 化碳分子的吸附与活化。以二氧化钛光催化剂为 例, $\mathrm{Pd}_{7} \mathrm{Cu}_{1}-\mathrm{TiO}_{2}$ 光催化转化二氧化碳生成甲烷的选 择性达到 $96 \%$ 。该催化位点设计还适用于具有可 见光响应的光催化剂, 可进行可见光下的二氧化 碳光催化转化。该工作为二氧化碳光催化转化的 反应位点设计提供了新的思路, 体现了晶格工程 在催化剂设计中的重要作用。该工作的同步辐射 X 射线吸收精细结构表征、光电子能谱表征、红外 光谱原位检测和理论模拟分别得到中国科学技术 大学宋礼教授、朱俊发教授、戚泽明研究员和江 俊教授的合作支持。

\section{References}

(1) Aresta, M.; Dibenedetto, A.; Angelini, A. Chem. Rev. 2014, 114, 1709. doi: $10.1021 / \mathrm{cr} 4002758$

(2) Maki-Arvela, P.; Simakova, I. L.; Salmi, T.; Murzin, D. Y. Chem. Rev. 2014, 114, 1909. doi: 10.1021/cr400203v

(3) Roy, S. C.; Varghese, O. K.; Paulose, M.; Grimes, C. A. ACS Nano 2010, 4, 1259. doi: 10.1021/nn9015423

(4) Habisreutinger, S. N.; Schmidt-Mende, L.; Stolarczyk, J. K. Angew. Chem. Int. Ed. 2013, 52, 7372. doi: 10.1002/ anie.201207199

(5) Tu, W.; Zhou, Y.; Zou, Z. Adv. Mater. 2014, 26, 4607. doi: 10.1002/adma.201400087

(6) Long, R.; Li, Y.; Chen, S.; Zheng, X.; Gao, C.; He, C.; Chen, N,; Qi, Z.; Li, S.; Jiang, J.; Zhu, J.; Xiong, Y. J. Am. Chem. Soc. 2017, doi: 10.1021 /jacs. 7 b00452

(7) Zhai, Q.; Xie, S.; Fan, W.; Zhang, Q.; Wang, Y.; Deng, W.; Wang, Y. Angew. Chem. Int. Ed. 2013, 52, 5776. doi: 10.1002/ anie. 201301473

(8) Li, R.; Hu, J.; Deng, M.; Wang, H.; Wang, X.; Hu, Y.; Jiang, H. L.; Jiang, J.; Zhang, Q.; Xie, Y.; Xiong, Y. Adv. Mater. 2014, 26, 4783. doi: 10.1002 adma.201400428 